\title{
KATEGORI ZONA RAWAN LONGSOR JALUR TRANSPORTASI BUNGUS TELUK KABUNG MENUJU SUNGAI PISANG DI KOTA PADANG.
}

\author{
Wirman Nofriadi \\ Program Studi Pendidikan Geografi \\ Fakultas Ilmu Sosial \\ Email: wirman.nofriadi@gmail.com
}

\begin{abstract}
ABSTRAK
Penelitian ini bertujuan untuk mengetahui dan menganalisis tentang penggunaan lahan, tekstur tanah, pelapukan batuan, kemiringan lereng, intensitas curah hujan, dan sebaran kelas zona rawan longsor sepanjang Jalur Transportasi Bungus Teluk Kabung menuju Sungai Pisang di Kota Padang. Jenis penelitian adalah penelitian deskriptif dengan metode survey. Pengambilan sampel penelitian diambil berdasarkan satuan lahan di daerah penelitian. Teknik analisis data yang digunakan adalah penskoran dengan overlay dari lima parameter yaitu: Tekstur Tanah, Pelapukan Batuan, Kemiringan Lereng, Curah Hujan dan Penggunaan lahan. Hasil penelitian ditemukan: 1) penggunaan lahan ditemukan pemukiman $33 \%$, pertanian lahan kering $22 \%$, semak belukar $22 \%$, dll 22\%. 2)tekstur tanah yang lebih dominan adalah liat berdebu sebanyak $44 \%$, pasir $33 \%$ dll $33 \%$. 3)pelapukan batuan berada dalam kategori tidak lapuk 33\%, lapuk sedang $22 \%$, lapuk ringan $22 \%$, dll 22\%, 4)kemiringan lereng bervariasi yaitu kategori datar $33 \%$ curam $22 \%$, sangat curam 22\%, dll 22\%. 5)curah hujan BMKG Teluk Bayur Kota Padang periode 2012-2016 dengan rata rata $368.82 \mathrm{~mm} / \mathrm{bln}$ dalam kategori sangat tinggi. 6) Kelas longsor Zona I, terdapat pada titik sampel 4, 5, 7, 9. Kelas longsor Zona II terdapat pada titik sampel 1, 8. Kelas longsor Zona III, terdapat pada titik sampel 2, 3, 6 .
\end{abstract}

Kata Kunci : Satuan Lahan, Longsor Sepanjang Jalur.

\section{ABSTRACT}

This study aims to identify and analyze about the land cover, texture of the soil, weathering, slope, rainfall intensity, and distribution of grade zones prone to landslides along Transportation lanes Bungus Teluk Kabung bay towards the Sungai Pisang in Padang. This type of research is descriptive research with survey method. Sample was taken by land area research. The data analysis technique used is scoring with overlay on five parameters are: soil texture, weathering of rocks, slope, rainfall and land cover. The research found: 1) found land cover 33\% residential, 22\% of dry land agriculture, underbush 22\%, etc 22\%, 2) the more dominant soil texture is a dusty clay as much as $44 \%$, sandy $33 \%$, etc $33 \% 3$ ) the weathering of rocks are in the categor of ylaw $33 \%$ rotten, mild $22 \%$ rotten, rotten was $22 \%$, etc $22 \%$. 4) varies the slope is flath $33 \%$ steep category 22\%, a very steep $22 \%$. Etc $22 \%$ 5) rainfall Teluk Bayur Padang BMKG 2012-2016 period to an average of $368.82 \mathrm{~mm} / \mathrm{mo}$ in very high category. 6) Class I avalance zone Is 4, 5, 7, 9. With Class II avalanche zone sample point 1, 8, Class landslides Zone III, are present in the sample point $2,3,6$.

Keywords: Land Force, Avalanche Along the Line.

1 Artikel ini ditulis dari skripsi penulis dengan judul Kategori Zona Rawan Longsor Jalur Transportasi Bungus Teluk Kabung Menuju Sungai Pisang di Kota Padang untuk wisuda periode Maret 2018 


\section{PENDAHULUAN}

Bencana alam merupakan peristiwa yang dapat diakibatkan oleh proses alam, baik yang terjadi oleh alam itu sendiri maupun diawali oleh tindakan manusia, yang menimbulkan resiko dan bahaya terhadap kehidupan manusia baik harta maupun jiwa. Karakteristik bencana alam ditentukan oleh keadaan lingkungan fisik seperti iklim, topografi, geologi, tanah, tata air, penggunaan lahan dan aktivitas manusia.

Sutikno (2001) menyatakan bahwa secara geologis, geomorfologis, dan

klimatologis Indonesia selalu menghadapi bencana alam yang berupa banjir, kekeringan, longsoran, letusan gunung api, dan gempa bumi, kejadian bencana alam di Indonesia cenderung meningkat dari waktu ke waktu, baik jenis maupun frekwensinya, demikian

juga dengan kerugian yang ditimbulkannya.

Gerakan tanah bentuk longsor lahan sangat banyak terjadi di Indonesia, hal ini disebabkan karena Indonesia merupakan daerah subduksi, sehingga mempunyai topografi yang bergunung gunung yang menjadikan lahan mempunyai lereng landai dan curam, dengan curah hujan yang tinggi dan kondisi geomorfologi yang cukup

kompleks di beberapa wilayah Indonesia, longsor lahan dianggap merupakan suatu hal yang sudah biasa terjadi (Hermon, 2008)

Menurut Anwar (2003), longsor terjadi secara alamiah jika disebabkan oleh faktor faktor alam yang dapat menimbulkan bencana dan merugikan manusia, aspek sosial ekonomi, serta lingkungan. Namun, terjadinya bencana dapat dipercepat karena dipicu oleh kecerobohan manusia. Seiring dengan apa yang dikatakan oleh Canuti et al (2003) dalam Alhasanah (2006), faktor penyebab tanah longsor secara alamiah meliputi morfologi permukaan bumi, penggunaan lahan, litologi, struktur geologi, dan kegempaan. Selain faktor alamiah, juga disebabkan oleh aktivitas manusia yang mempengaruhi suatu bentang alam, seperti kegiatan pertanian, pembebanan lereng, pemotongan lereng dan penambangan.

Bencana tanah longsor dampaknya bersifat lokal (dibandingkan dengan gempa bumi dan letusan gunung api), sering terjadi dan dapat mematikan manusia karena kejadiannya yang tiba tiba. Kejadian tanah longsor di Sumatera Barat pada tahun 2003-2005 terjadi di beberapa titik lokasi yang mengakibatkan korban meninggal dunia 63 orang, korban luka luka 25 orang, rumah hancur 16 unit, rumah rusak 14 unit, lahan pertanian rusak 540 ha, dan jalan putus $60 \mathrm{~m}$ (PVMBG 2007).

Daerah yang berpotensi mengalami bencana alam biasanya daerah yang berada di sekitar wilayah pegunungan, perbukitan, memiliki curah hujan yang tinggi dan mempunyai lereng yang curam, salah satu daerah dengan kondisi seperti ini adalah Kelurahan Sungai Pisang Kecamatan Bungus Teluk Kabung yang berada di Kota Padang. Kec Bungus Teluk Kabung merupakan 
daerah yang mempunyai tingkat kerawanan yang cukup tinggi terhadap kejadian bencana tanah longsor, walaupun selama ini korban jiwa akibat bencana alam tersebut tidak begitu banyak tapi wilayah ini dapat dipastikan setiap tahunnya selalu terjadi bencana tanah longsor baik yang berskala besar maupun kecil, seperti yang terjadi di Kelurahan Sungai Pisang, Kecamatan Bungus Teluk Kabung, Kota Padang pada 18 juni 2016 yang mengakibatkan sebanyak 13 titik longsor memutus akses ke daerah Sungai Pisang, juga mengakibatkan enam tiang listrik roboh sehingga membuat 1,400 jiwa atau 312 kepala keluarga terpaksa hidup dengan gelap gulita.

Menurut Sitorus (2006), penyebab terjadinya bencana longsor secara umum dapat dibedakan atas 3 yakni; 1) kondisi alam yang bersifat statis, seperti kondisi geografi, topografi, dan karakteristik sungai, 2) peristiwa alam yang bersifat dinamis, seperti perubahan iklim global, pasang surut, land

subsidence, sedimentasi dan sebagainya, dan 3) aktifitas sosial ekonomi manusia yang sangat dinamis, seperti deforestasi (pengundulan hutan), konversi lahan pada kawasan lindung, pemanfaatan sempadan sungai/saluran untuk perumahan, pemanfaatan wilayah retensi banjir, perilaku masyarakat, keterbatasan prasarana dan sarana pengendali banjir dan sebagainya.

Longsor merupakan merupakan suatu fenomena alam yang selalu berhubungan dengan datangnya musim hujan, terjadi secara tiba tiba dalam waktu yang relatif singkat pada suatu tempat tertentu dengan tingkat kerusakan yang sangat berat, bahkan kehilangan nyawa penduduk yang bermukim di sekitarnya (sitorus ;2006). Menurut utoyo et al (2001) dan Canuti et al (2003), bencana longsor selain diakibatkan oleh karakteristik wilayah, juga disebabkan oleh aktifitas manusia dalam hal pemenuhan kebutuhannya tanpa memperhatikan keberlanjutan dari sumber daya alam.

Longsor merupakan bagian dari gerakan tanah yang tergolong pada gerakan massa yang sangat erat kaitannya dengan proses proses alamiah pada suatu bentang alam. Secara umum longsor disebabkan oleh; 1) adanya lereng yang cukup curam sehingga masa tanah dapat bergerak atau meluncur kebawah, 2) adanya lapisan dibawah permukaan tanah yang kedap air dan lunak sebagai bidang luncur, dan

3) adanya cukup air didalam tanah sehingga lapisan massa tanah yang tepat di atas lapisan kedap air tersebut menjadi jenuh.

Menurut Marsaid (2002) bencana longsor lahan dapat diakibatkan oleh faktor alamiah dan non faktor ilmiah. Faktor alamiah penyebab terjadinya longsor lahan adalah: 1) kondisi geologi yaitu adanya jalur jalur patahan dan rekahan batuan yang mengakibatkan kondisi lereng yang mempunyai kemiringan $>30 \%$ dan tumpukan tanah lempung pasiran diatas batuan kedap air berupa andesit dan breksi andesit, 2) kondisi curah hujan yang cukup tinggi tiap tahun, dan 3) sistem hidrologi (tata air) pada daerah lereng. Sedangkan yang tergolong pada faktor non ilmiah adalah; 1) pembukaan hhutan secara sembarangan, 2) penanaman jenis 
tanaman yang terlalu berat dengan jarak tanam yang terlalu rapat, dan 3) pemotongan tebing/lereng untuk jalan pemukiman secara tidak teratur.

Berdasarkan uraian dari latar belakang diatas maka peneliti tertarik untuk mngetahui unsur apa saja penyebab terjadinya longsor yang peneliti tuangkan dalam sebuah bentuk penelitian yang berjudul "Kategori Zona Rawan Longsor Jalur Transportasi Bungus Teluk Kabung Menuju Sungai Pisang Di Kota Padang".

\section{METODE PENELITIAN}

Jenis Penelitian. Penelitian yang dilakukan termasuk jenis penelitian deskriptif dengan metode yang digunakan adalah metode survey. Manurut Arikunto (1995) penelitian deskriptif merupakan penelitian yang dimaksud untuk mengumpulkan informasi mengenai status suatu gejala yang ada yaitu keadaan menurut apa adanya pada saat penelitian dilakukan

Populasi. Menurut Sumaatmaja (1988:112-113), populasi adalah keseluruhan gejala, individu, kasus dan masalah yang diteliti, yang ada didaerah penelitian yang menjadi objek penelitian. Populasi dalam penelitian ini adalah seluruh daerah rawan longsor di sepanjang Jalur Transportasi Bungus Teluk Kabung menuju Sungai Pisang di Kota Padang.

Sampel. Menurut Sumaatmaja (1988:112-113) adalah bagian dari populasi yang mewakili populasi yang bersangkutan. Sampel harus memiliki karakteristik tertentu yang sesuai dengan penelitian yang dilakukan.
Penentuan areal sampel menggunakan Purposive Sampling, yaitu penarikan yang berdasarkan dengan satuan lahan dengan pertimbangan tertentu untuk menentukan sampel penelitian. Pengambilan sampel areal penelitian berdasarkan satuan lahan yang berada di sepanjang Jalur Transportasi Bungus Teluk Kabung menuju Sungai Pisang di Kota Padang dapat kita ambil 9 sampel yaitu :

V2.II.Keb.And.Qpt, V4.IV.Keb.And.Qpt, V4.IV.Keb.Kam.Qpt, M1.II.Keb.Kam.Qh, M1.II.Mang.Kam.Qh, V2.II.Keb.Kam.Qpt. M1.II.Keb.Gley.Qh, V2.II.Keb.Gley.Qpt, M1.II.Per.Gley.Qh.

1. Bahan dan Alat Penelitian

a. Bahan Penelitian

1). PetaTopografi skala 1: 50.000

2). Peta Tanah skala 1: 50.000

3). Peta Geologi skala 1: 50.000

4). Peta Penggunaan Lahan skala 1: 50.000

5). Data Curah Hujan

b. Alat yang

Digunakan 1). GPS

2). Abney Level

3). Pita Ukur

4). Cangkul, Pisau dan Plastik

5). Buku label dan karet gelang

6). Kamera

7). Spidol dan buku catatan

2. Jenis Data.

Data yang dikumpulkan berupa data primer dan sekunder. Data primer adalah data yang diperoleh secara langsung di 
lapangan. Sedangkan data sekunder adalah data yang diperoleh dari instansi terkait.

a. Data primer (berupa bentuk lahan, karakteristik lahan, curah hujan, vegetasi penutup lahan, dan aktivitas manusia).

b. Data sekunder (data curah hujan di daerah penelitian).

3. Tahap Penelitian

1. Tahapan pra lapangan

a. Studipustakauntuk pengumpulan bahan yang berkaitan dengan objek kajian penelitian.

b. Mengumpulkan bahan bahan penelitian berupa peta topografi, peta tanah, peta geologi dan peta satuan lahan penelitian.

c. Penentuan titik sampel areal berdasarkan satuan medan sebagai sampel.

2. Tahapan lapangan

a. Mencocokan peta satuan medan sementara dengan keadaan sebenar nya di lapangan (survey lapangan).

b. Mengamati dan mengukur karakteristik fisik wilayah untuk

Gambar I. Peta Sampel Penelitian menentukan penyebab rawannya longsor.

3. Tahap pasca lapangan.

a. Menganalisis data untuk menentukan penyebab rawan longsor.

b. Pengambilan kesimpulan tentang penyebab rawan longsor.

4. Teknik pengambilan sampel

Satuan pemetaan dalam penelitian ini adalah satuan lahan. Satuan lahan diperoleh melalui overlay peta satuan bentuklahan dengan peta lereng, tanah, litologi dan penggunaan lahan. Setiap satuan lahan yang bervariasi akan di ambil satu untuk mewakili sebagai sampel. Pengambilan sampel dilakukan dengan teknik purposive sampling. Penentuan zona rawan longsor dilihat dari satuan lahan yang dekat dengan akifitas manusia dan jalan raya sehingga pengambilan sampel

juga memperhatikan aspek tersebut. Untuk lebih jelasnya dapat kita lihat pada peta Sampel Penelitian di bawah ini: 


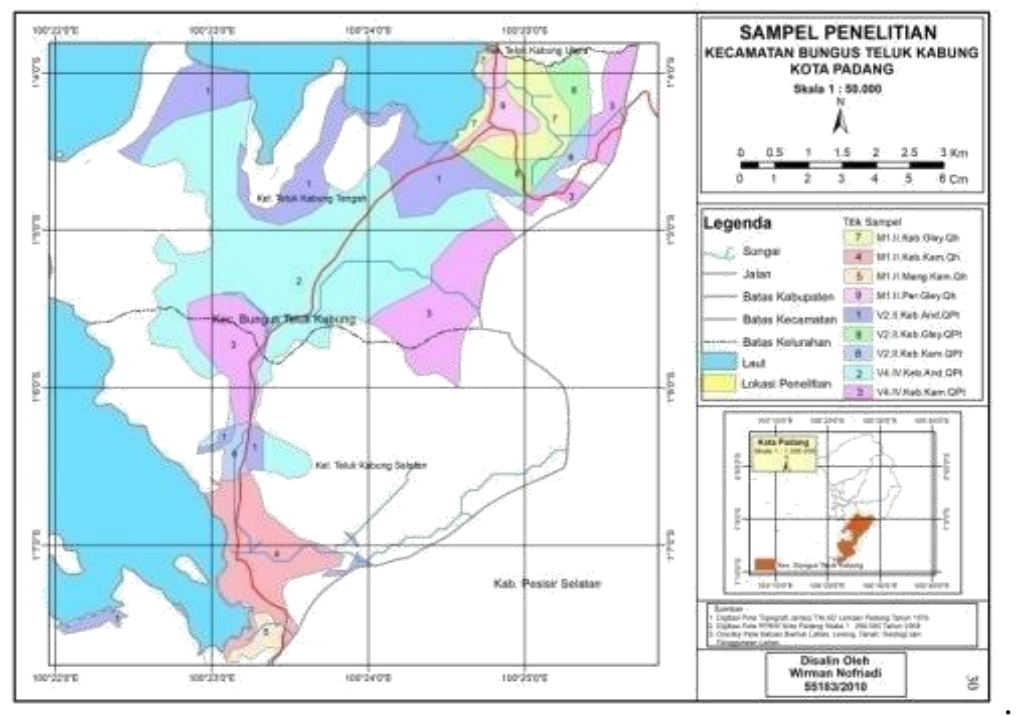

Sumber: Overley dari peta satuan bentuk lahan, lereng, tanah, geologi, dan penggunaan lahan

5. Teknik Analisis Data

Teknik analisa data yang digunakan dalam penelitian ini adalah dengan cara penjumlahan (scoring). Metode pengharkatan atau scoring merupakan suatu cara menilai potensi lahan dengan memberikan nilai pada masing masing karakteristik lahan, sehingga dapat dihitung nilainya dan dapat ditentukan harkatnya dengan menggunakan formula yang dikemukakan oleh Dibyosaputro (1999), yaitu sebagai berikut:

$$
\mathrm{i}=
$$

Keterangan

$\mathrm{I}=$ Interval

$\mathrm{C}=$ Jumlah harkat tertinggi (25)

$\mathrm{B}=$ Jumlah harkat terendah (5)

$\mathrm{K}=$ Jumlah kelas yang diinginkan (3)

Berdasarkan rumus diatas dapat kita lihat kelas Zona Rawan Longsor Sebagai berikut;
Tabel 1. Kelas Zona Rawan Longsor

\begin{tabular}{|l|l|l|}
\hline Zona & Interval & $\begin{array}{l}\text { Tingkat zona } \\
\text { rawan } \\
\text { Longsor }\end{array}$ \\
\hline I & $6-12$ & Rendah \\
\hline II & $13-18$ & Sedang \\
\hline III & $>19$ & Tinggi \\
\hline
\end{tabular}

Sumber : interval tingkat zona rawan longsor zuidam dan cancelado dimodifikasi

Zona I : Rendah, Tidak ada sama sekali longsor.

Zona II : Sedang, peluang terjadi longsor 1 kali dalam 5 tahun

Zona III: Tinggi, peluang terjadi longsor 2 kali dalam 5 tahun.

\section{HASIL DAN PEMBAHASAN}

Tekstur Tanah. Berdasarkan pengujian labor Tekstur Tanah dari 9 titik sampel penelitian, terdapat 1 titik sampel dengan tekstur tanah liat, dalam perhitungan Harkat Tingkat Bahaya Longsor menurut Zuidam dan Cancelado tekstur tanah liat termasuk 
kriteria agak halus dan memiliki Harkat 4 dalam mempengaruhi Longsor. 4 titik sampel dengan tekstur tanah Liat Berdebu, dalam harkat longsor Zuidam dan Cancelado Liat Berdebu kriterianya Halus, dan memiliki harkat 5 yang mempengaruhi kelas longsor sangat tinggi. 1 titik sampel dengan Tekstur Tanah Lempung Berdebu, dengan kriteria Sedang yang mempunyai harkat 3 dengan pengaruh kelas longsor sedang, 1 titik sampel memiliki tekstur tanah liat berpasir, dengan kriteria liat berpasir agak halus, dan memiliki harkat 4 yang tergolong pada kelas zona longsor tinggi. Dan 2 titik sampel memiliki tekstur tanah berpasir dengan kriteria kasar dan memiliki harkat 1, tergolong pada zona longsor rendah.

Pelapukan Batuan. Berdasarkan pengamatan dari 9 titik sampel, pada daerah penelitian terdapat 3 titik sampel tergolong pada tidak lapuk, karena tidak adanya nampak pelapukan dan batuan sesegar kristal yang memiliki harkat 1 dengan pengaruh tingkat longsor rendah, 2 titik sampel tergolong pada Lapuk Ringan, karena pelapukan hanya terjadi pada Diskontinuitas terbuka dan menimbulkan perbedaan warna, menurut perhitungan Zuidam dan Cancelado memiliki harkat 2 dengan pengaruh longsor sedang. 2 titik sampel tergolong pada lapuk sedang, karena kurang dari setengah batuan terintegrasi menjadi tanah, bagian tengah batuan masih segar, mempunyai harkat 3 yang dengan pengaruh longsor agak tinggi. 1 titik sampel dengan kategori lapuk kuat, karena lebih dari setengah batuan terdekomposisi atau terdesintegrasi pada tengah batuan sampai seluruhnya berubah menjadi tanah, memiliki harkat 4 dengan pengaruh longsor tinggi. 1 titik sampel dengan kategori lapuk sempurna, karena seluruh batuan sudah berubah warna dan lapuk, serta sudah nampak luas seperti tanah, yang memiliki harkat 5 dengan pengaruh longsor sangat tinggi.

Kemiringan Lereng. Berdasarkan pengukuran kemiringan lereng dengan menggunakan Abney Level pada 9 titik sampel memiliki tingkat kemiringan yang berbeda yaitu 3 titik sampel dengan lereng datar ( 0-8 \%) dengan harkat 1 dengan kriteria rendah pengaruhnya terhadap longsor, 1 titik

sampel berlereng Landai(6-14\%), dengan harkat 2, dan pengaruh lonsornya sedang, 1 titik sampel dengan Lereng agak landai (15-25\%) dengan harkat 3, yang mana menurut perhitungan Zuidam dan Cancelado memiliki kriteria agak tinggi pengaruh longsornya, 2 titik sampel dengan Lereng Curam (25-40 \%) dengan harkat 4 dan memiliki kriteria Tinggi pengaruh longsornya, 2 titik sampel dengan Lereng Sangat Curam (>40 \%) dengan harkat 5, dan pengaruh longsor sangat tinggi.

Curah Hujan. Berdasarkan pengolahan data yang diperoleh dari BMKG Teluk Bayur Kota Padang, wilayah penelitian ini berada pada iklim sangat basah, dan perhitungan Curah Hujan perbulan pada periode 2012-2016 (5 tahun) adalah $4425.86 \mathrm{~mm} /$ th dengan rata rata bulanan $368.82 \mathrm{~mm} / \mathrm{bln}$, menurut Schmit Ferguson jika curah hujan $>120 \mathrm{~mm} / \mathrm{bln}$ berada pada kriteria sangat tinggi tingkat kelongsorannya. 
Tutupan Lahan. Berdasarkan teori tutupan lahan dapat menjadi faktor pengontrol gerakan tanah daan meningkatkan resiko gerakan tanah, karena pemanfaatan lahan berpengaruh terhadap tutupan lahan yang ada (Karnawati dalam Anwar 2012). Hasil survey lapangan pada 9 titik sampel, diperoleh 3 titik sampel pemukiman, 1 titik sampel lahan terbuka, 2 titik sampel pertanian lahan kering, 2 titik sampel semak belukar, dan 1 titik sampel hutan. Menurut teori Zuidam dan Cancelado dalam Hermon (2012)

yang dimodifikasi pemukiman mempunyai harkat 2 dengan kriteria sedang mempengaruhi longsor, lahan terbuka mempunyai harkat 5 dengan kriteria Sangat Tinggi mempengaruhi longsor, Pertanian Lahan Kering mempunyai harkat 4 dengan kriteria tinggi, Semak Belukar mempunyai harkat 3 dengan kriteria agak tinggi mempengaruhi longsor, dan 1 titik sampel hutan mempunyai harkat 1 dengan kategori Rendah dalam mempengaruhi longsor.

Berdasarkan pembahasan 5 variabel diatas maka sebaran kelas zona rawan longsor tersebar pada jumlah harkat dari kelima variabel dengan jumlah 6-12 termasuk pada kategori Zona I (rendah) yang berarti tidak ada sama sekali longsor, dengan jumlah 13-19 termasuk pada kategori Zona II, Sedang dengan peluang terjadi longsor 1 kali dalam 5

Gambar 2. Peta Hasil Penelitian tahun, sedangkan jumlah harkat $>19$ termasuk pada kategori Zona III, Tinggi dengan peluang terjadi longsor 2 kali dalam 5 tahun.

Hasil yang diperoleh dari 9 titik sampel, ditemui 4 titik sampel terdapat pada kategori Zona I yaitu rendah tidak ada sama sekali longsor, 2 titik sampel terdapat pada kategori Zona II yaitu sedang, dengan peluang terjadi longsor 1 kali dalam 5 tahun, sedangkan 3 titik sampel termasuk kedalam kategori Zona III yaitu dengan tingkat longsor tinggi, denagn peluang terjadi longsor 2 kali dalam 5 tahun.

Peta menjelaskan warna biru tua untuk kategori kawasan rendah zona rawan longsor, kuning untuk kategori kawasan sedang zona rawan longsor, dan warna kuning tua mempunyai kategori kawasan tinggi zona rawan longsor. Pada peta dapat dilihat yang termasuk kedalam zona rawan longsor rendah adalah titik sampel 4, titik sampel 5, titik sampel 7, titik sampel 9. sedang terdapat pada titik sampel 1 , dan titik sampel 8, sedangkan yang termasuk kedalam zona rawan longsor tinggi adalah titik sampel 2, titik sampel 3 dan titik sampel 6 .

Untuk lebih jelasnya dapat dilihat peta hasil penelitian zona rawan longsor di Sepanjang Jalur Transportasi Bungus Teluk Kabung menuju Sungai Pisang di Kota Padang pada gambar 2. 


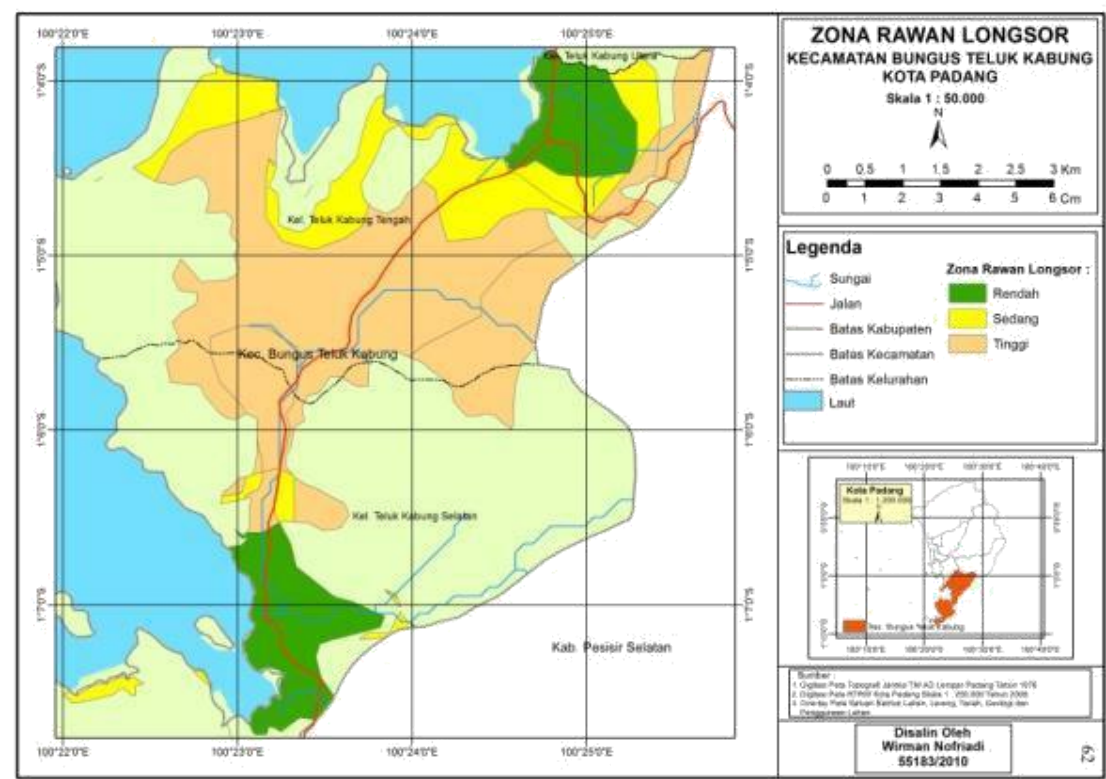

Sumber: overley peta satuan bentuk lahan, lereng, tanah, geologi dan penggunaan lahan

\section{PENUTUP}

\section{Kesimpulan}

Berdasarkan hasil pengolahan data dari penelitian yang dilakukan maka dapat di ambil kesimpulan sebagai

berikut: Penggunaan lahan yang terdapat di wilayah penelitian di temukan lahan terbuka pada titik sampel 2, pertanian lahan kering pada titik sampel 3 dan titik sampel 7, semak belukar pada titik sampel 6 dan titik sampel 8, sedangkan hutan mangrove pada titik sampel 5 .

Tekstur tanah yang terdapat di daerah penelitian yaitu liat pada titik sampel 1, liat berdebu pada titik sampel 2, 3, 6, dan 8, pasir terdapat pada titik sampel 4 dan 7, lempung berpasir pada tiktik sampel 5, dan pasir berlempung pada titik sampel 9.

Pelapukan batuan yang di temukan di daerah penelitian yaitu tidak lapuk terdapat pada titik sampel 5, 7 dan 9, lapuk ringan pada titik sampel 1 dan 4 , lapuk sedang terdapat pada titik sampel
3 dan 8, lapuk kuat terdapat pada titik sampel 2, dan lapuk sempurna pada titik sampel 6.

Kemiringan lereng yang berada didaerah penelitian yaitu dataran pada titik sampel 4, 7 dan 9, agak landai pada titik sampel 1, landai pada titik sampel 5 dan 9, curam pada titik sampel 2 dan 8 , sangat curam pada titik sampel 6 .

Curah hujan berdasarkan pengolahan data yang diambil dari BMKG Teluk Bayur Kota Padang periode 2012-2016 wilayah penelitian berada pada tingkat curah hujan sangat tinggi yaitu dengan rata rata 5 tahun $4425.86 \mathrm{~mm} /$ th dengan rata rata bulanan $368.82 \mathrm{~mm} / \mathrm{bln}$ maka berada dalam iklim sangat basah.

Sebaran zona rawan longsor sepanjang jalur bungus teluk kabung menuju sungai pisang terdapat 3 (tiga) kelas yaitu: Kelas I rendah terdapat pada titik sampel 4 (M1.II.Keb.Kam.Qh), titik sampel 5 (M1.II.Keb.Mang.Qh), titik sampel 7 (M1.II.Keb.Gley.Qh) dan titik sampel 9 
(M1.II.Per.Gley.Qh). Kelas II Sedang terdapat pada titik sampel 1 (V2.II.Keb.And.Qpt) dan titik sampel 8 (V2.II.Keb.Gley.Qpt). sedangkan Kelas III atau Tinggi terdapat pada titik sampel 2 (V4.IV.Keb.And.Qpt), titik sampel 3 (V4.IV.Keb.Kam.Qpt), dan titik sampel 6 (V2.II.Keb.Kam.Qpt).

2. Saran

Berdasarkan kesimpulan diatas maka penulis dapat memberikan saran sebagai berikut:

Pada penggunaan lahan sebaiknya di manfaatkan sebagai lahan perkebunan, yaitu dengan menanam tumbuhan jangka panjang, sehingga akar dari tumbuhan tersebut cukup kuat untuk menahan tanah yang mudah terjadinya longsor.

Dengan tekstur tanah yang beragam sebaiknya masyarakat memahami pemanfaatan lahan berdasarkan tekstur tanah yang terdapat di wilayah

penelitian, sehingga dengan pemanfaatan lahan yang tepat bisa mengurangi terjadinya longsor.

Pada pelapukan batuan sedang hingga lapuk kuat, perlu adanya kerjasama antara masyarakat dengan instansi terkait untuk bagaimana cara mengurangi resiko longsor dengan membeton lereng pada titik rawan longsor sepanjang Jalur Transportasi Bungus Teluk Kabung menuju Sungai Pisang di Kota Padang.

Masyarakat dan pemerintah terkait bekerja sama untuk menanan tanaman yang bisa mengurangi terjadi longsor yang sesuai dengan tingkat kelerengan di daerah penelitian

Dengan curah hujan yang sangat tinggi di daerah penelitian maka sebaiknya masyarakat lebih memperhatikan drainase lereng, drainase permukaan, serta bawah permukaan.

Setelah ditemukan titik zona rawan longsor pada wilayah penelitian sebaiknya masyarakat meminta kepada instansi terkait untuk memberikan rambu rambu di setiap lokasi yang berkemungkinan akan terjadinya longsor.

\section{DAFTAR PUSTAKA}

Alhasanah,F. 2006. Pemetaan dan Analisis Daerah Rawan Tanah Longsor Serta Upaya Mitigsinya Menggunakan Sistem Informasi Geografis (Studi Kasus Kecamatan Sumedang Selatan, Kabupaten Sumedang, Propinsi Jawa Barat). Bogor. Sekolah Pasca Sarjana, Institut Pertanian Bogor.

Anwar, Herryzal. 2003. Mengurangi Dampak Bencana Longsor, kompas, jakarta. Halm 10.

Arikunto, Suharsimi. 1995. Manajemen Penelitian. Jakarta: Rineka Cipta.

Canuti et al. 2003. Lanslide Hazard For Archaelogical Heritage; Tha Case Of Tharros In Italy. Landslide News. 14/15;40-43.

Dibyosaputro.1999. Longsor Lahan Di

Kecamatan Samigaluh Kabupaten Kulon Progo DIY. Majalah Geografi Indonesia. 23.3-34.

(DVMBG) Direktorat Vulkanologi dan Mitigasi bencana Geologi, 2007. Pengenalan gerakan tanah 
http://www.merapi.

Vsi.esdm.go.id/?static/gerakan tanah /pengenalan.htm(10 Mei 2016)

Hermon dan Triyatno. 2001. Tingkat Bahaya dan Resiko Longsor Di Gunung Padang Kota Padang. Laporan Penelitian LEMLIT UNP. Padang

Hermon, Dedi. Dkk.2008. Metode dan teknik penelitian geografi tanah aplikasi instrumen dan acuan penelitian geografi fisik. Padang: yayasan jihadul khairi center

Hermon, Dedi.dkk.2012. Mitigasi Bencana Hidrometeorologi. Padang UNP Press.

Marsaid.2002. Kebijakan Pemerintah Kabupaten Purworejo Dalam Penanggulangan Bencana Alam Tanah Longsor. Makalah Dalam Simposium Nasional Pencegahan Bencana Sedimen. Kerjasama ISDM, JICA, DIRJEN Sumberdaya Air. Yogyakarta. Hal 50-58.

Sutikno. 2001. Gempa Bumi dan agihannya di Indonesia, upaya minimalisasi kerugian akibat gempa pada rumah sederhana. Makalah ilmiah teknik sipil. 2001. Surabaya. Sumaatmaja, Nursid. 1988. Studi Pendekatan dan analisa keruangan. Bandung, Alumni,

Sumaatmaja, Nursid. 1988. Studi Pendekatan dan analisa keruangan. Bandung, Alumni,

Sitorus. 2006. Pengembangan Lahan Berpenutupan Tetap Sebagai Kontrol Terhadap Faktor Resiko
Erosi Dan Bencana Longsor. Makalah. Lokakarya penataan ruang sebagai wahana untuk meminimalkan potensi kejadian bencana longsor. Jakarta 7 maret 2006.

Zuidam. 1979. Terrain Analysis and Classification Using Aerial Photograph.

Geomorphological Approach. ITC Textbook of Photo Interpretasion Netherland. 7: 223. 